\title{
HEE-GER: a systematic review of German economic evaluations of health care published 1990-2004
}

\author{
David LB Schwappach*1,2 and Till A Boluarte ${ }^{2}$
}

\author{
Address: ${ }^{1}$ Research Institute for Public Health and Addiction, Konradrstrasse 32, 8031 Zurich, Switzerland and ${ }^{2}$ Health Policy, Faculty of Medicine, \\ University Witten-Herdecke, Alfred-Herrhausen-Str. 50, 58448 Witten, Germany \\ Email: David LB Schwappach* - David.Schwappach@isgf.unizh.ch; Till A Boluarte - Till.Boluarte@uni-wh.de \\ * Corresponding author
}

Published: 12 January 2007

BMC Health Services Research 2007, 7:7 doi:10.1186/1472-6963-7-7

This article is available from: http://www.biomedcentral.com/1472-6963/7/7

(c) 2007 Schwappach and Boluarte; licensee BioMed Central Ltd.

This is an Open Access article distributed under the terms of the Creative Commons Attribution License (http://creativecommons.org/licenses/by/2.0), which permits unrestricted use, distribution, and reproduction in any medium, provided the original work is properly cited.
Received: 14 August 2006

Accepted: 12 January 2007

\begin{abstract}
Background: Studies published in non-English languages are systematically missing in systematic reviews of growth and quality of economic evaluations of health care. The aims of this study were: to characterize German evaluations, published in English or German-language, in terms of various key parameters; to investigate methods to derive quality-of-life weights in cost-utility studies; and to examine changes in study characteristics over the years.
\end{abstract}

Methods: We conducted a country-specific systematic review of the German and English-language literature of German economic evaluations (assessment of or application to the German health care system) published 1990-2004. Generic and specialized health economic databases were searched. Two independent reviewers verified fulfillment of inclusion criteria and extracted study characteristics.

Results: The fulltexts of 730 articles were reviewed of which 283 fulfilled all entry criteria. $32 \%$ of included studies were published in German-language. $51 \%$ of studies evaluated pharmaceuticals and $63 \%$ were cost-effectiveness analyses. Economic appraisals concentrate on few disease categories and important health areas are strongly underrepresented. Declaration of sponsorship was associated with article language (49\% English articles vs. $29 \%$ German articles, $p<0.001$ ). The methodology used to obtain quality-of-life weights in published cost-utility studies was very diverse, poorly reported and most studies did not use German patients' or community health state valuations.

Conclusion: Many of the German-language evaluations included in our study are likely to be missing in international reviews and may be systematically different from Englishlanguage reviews from Germany. Lack of transparency and adherence to recommended reporting practices constitute a serious problem in German economic evaluations. 


\section{Background}

Economic evaluation of health care has evolved as an important tool for assessing the costs and benefits of health care and a large amount of evaluation studies has been published during the last decades. Several systematic reviews have been conducted that assessed the characteristics and quality of published studies [1-4]. The main conclusions that can be drawn from these studies is that adherence to methodological standards is increasing but still far from perfect. For example, in an analysis of pharmacoeconomic submissions to the Australian Pharmaceutical Benefits Scheme, $67 \%$ of submissions had significant problems [5]. The majority of problems identified (64\%) were deemed avoidable. Neuman et al. report in an analysis of cost-utility studies that in only $73 \%$ of the studies published 1998-2001, the authors clearly presented the study perspective [1]. In a recent analysis of cost data in economic evaluations conducted alongside randomized controlled trials, only $37 \%$ of the reviewed evaluations presented a cost-effectiveness ratio or estimated net benefits and only $57 \%$ of these reported the uncertainty of this statistic [6]. However, these reviews have covered the English-language literature only, and analyses published in languages other than English are therefore systematically missing. However, as evaluation studies are highly context dependent, it is likely that many studies are being published in the languages of the countries whose health care systems have been addressed. These country-specific analyses, often published in national journals, may also have considerable impact on local decision makers. Until now, no systematic review has been conducted to assess growth, characteristics and quality of German economic evaluations. The aim of this study was to overcome this gap and to 1) analyze in which journals and in which language German economic evaluations have been published; 2) describe the characteristics of the studies in terms of various key parameters, such as type of evaluation, study design, covered diseases, study perspective, funding sources and others; 3 ) examine changes in study and publication characteristics over the years and 4) investigate methods to derive quality-of-life weights in cost-utility. While our study included all types of full economic evaluations, we paid special attention to cost-utility-analyses, the methods used to derive utilities for calculation of quality-adjusted life years (QALYs) in published studies and, in particular, whether preferences have been elicited from German patients or community members.

\section{Methods}

\section{Literature search and study selection}

We searched the databases Embase, Pubmed, Econlit (silverplatter), Cinahl, NHS-Pharmline, NHS EED, and OHE HEED for relevant articles. The searches were conducted in April 2005. In addition, the references of retrieved articles were manually searched for further material. The rel- evant volumes of a German-language health economic journal were completely hand searched for relevant articles as this journal is not systematically covered in international databases [7]. We also contacted a list of German health economists and recognized authors $(n=63)$ via email and asked to provide us their bibliographic data. Of those, $17(27 \%)$ responded and sent their publication record and relevant material. As the use or translation of technical terms for indexing non-English literature in international databases is often inconsistent or errant we defined a search strategy with high sensitivity but low specificity $[8,9]$. The search strategy consisted of freetext and MeSH terms related to economic evaluation. The resulting hits were filtered for the occurrence of the terms "German" or "Germany" in any field. The retrieved records were further refined for the relevant year range and, where available, limited to journal articles. The search strings are provided in the Appendix (see Additional file 1). Studies were included in the review when they fulfilled all of the following inclusion criteria:

- Full economic evaluation, i.e., comparative analysis of costs and outcomes of at least two alternatives;

- Applied study (trial generating primary data or modeling of secondary data). Reviews, letters, abstracts, methodological and general articles were excluded;

- Assessment of or application to the German health care system;

- Journal articles, i.e., exclusion of books, HTA reports, grey literature;

- Published between 1990-2004 (i.e., after German reunification);

- Published in English or German-language

We did limit our analysis to evaluations published in official journals to assess those publications that have at least undergone some basic quality control. While, for example, some newer Health Technology Assessment reports may report original data analysis and would have therefore fitted our inclusion criteria in principle, they are usually not subject to external standardized peer review. It is also often hard to define what constitutes a HTA report since they may be published as grey literature by non-official agencies.

\section{Data extraction and critical appraisal}

We developed a checklist comparable to that used by other researchers to extract data from the fulltexts alongside review $[1,10]$. We collected details on study objective, intervention type and disease category, design, methodol- 
ogy and background data such as sponsorship. The data extraction form did not include explicit quality ratings. As one of our interests was the investigation of health effects assessment in cost-utility studies, data relating to health and preference measurement methodology were extracted in detail. We recorded the health measurement instrument used, the technique used for valuing health states, and the groups of individuals from whom quality of life data and valuations were obtained. We also compared the extracted data relating to utility measurement and reporting of QALY calculation against criteria recommended by Stalmeier et al. [11] and Richardson and Manca [10]. These criteria include, e.g., reporting of elicitation procedure, sample size, anchor states, and others. For all studies, we used only the information provided in the original publication. However, in case the published methodology regarding health status measurement provided in costutility studies was not sufficiently detailed to extract the data as needed but authors referred to other studies as data source, these references were obtained to extract the relevant information. For example, if authors cited a second study as source for utilities, we obtained this article to determine whether this study contained information on utility elicitation. Each paper was independently read by a single researcher. A random sample of $10 \%$ of studies was assessed by two reviewers to determine interrater reliability for each item. Cost-utility studies were all reviewed by both reviewers. Reviewers were also allowed to defer studies in case they were uncertain about one or more items. These studies were assessed by a second reviewer and discussed in consensus meetings to resolve discrepancies. After critical appraisal, information collected in data extraction forms were transferred to an electronic database.

\section{Analysis of data}

Kappa statistics (K) were calculated to assess interrater reliability for each item. We analyzed the distribution of extracted categories of economic evaluations and investigated differences between journal specialty (medical vs. health care sciences journals, as defined by the ISI Journal Citation Reports subject category listing) and German and English-language articles. To assess developments over time, we defined the year ranges 1990-1998 and 19992004. Comparisons were made using chi-square tests. A pvalue of less than 0.05 was considered significant. All analyses were performed using STATA 9 software [12].

\section{Results}

The systematic literature search initially identified 2,158 candidate articles, of which 724 were selected for fulltext retrieval (figure 1). The majority of articles were discarded at this initial stage mainly because they were duplicates, or it was obvious from the bibliographic data that they violated basic inclusion criteria. Further 9 articles were iden- tified through hand searching or submitted by the contacted experts. 3 articles were not available as fulltexts, neither from the publisher or document suppliers nor directly from the authors. In summary, the fulltexts of 730 articles were reviewed. 447 articles were dropped after the critical appraisal because they failed one or more inclusion criteria. Interrater reliability (K) was assessed on a sample of 90 studies ( $10 \%$ random sample + all remaining 17 CUAs not included in this sample by random). $\mathrm{K}$ was 0.978 (95\% CI $0.934-1.0)$ for study inclusion, i.e., fulfillment of all entry criteria. $\mathrm{K}$ for all other items ranged from 0.921 (95\% CI $0.885-1.0)$ for primary disease category to 1.0 for the items 'study design' and 'study setting'. Overall, a very good level of agreement was observed [13]. 283 studies fulfilled all entry criteria.

\section{Basic characteristics of included studies}

As can be seen from figure 2, publication of German health economic studies has steadily increased until 1998 and has since then remained relatively stable with approximately 30 studies published per year. Of the included studies, 91 (32\%) were published in German-language and no stable trend towards internationalization (in terms of publication in English-language) could be observed. The studies concentrate on few journals, and 134 out of 151 journals (89\%) published less than three German economic evaluations between 1990 and 2004 (table 1). The vast majority of studies (79\%) was published in medical journals in contrast to specialized health economic or health care sciences journals. The $91 \mathrm{Ger}-$ man-language articles were published in 39 different German journals (37 medical and 2 health economics/ services journals) with a median of 1 evaluation published per journal. Only 21 of these journals are listed in the ISI Journal Citation Reports.

Table 2 reports the characteristics of the included studies. Of the 283 studies that fulfilled all entry criteria, $0.4 \%$ were cost-benefit analyses, $6 \%$ cost-utility analyses, $14 \%$ cost-minimization analyses, $18 \%$ cost-effectiveness analyses with "life years gained" as outcome measure and 45\% were cost-effectiveness analyses that used a clinical outcome as measure of effectiveness. Many studies (17\%) were observational studies with information on costs that left health outcomes disaggregated and used no summary measure of benefit (cost consequence analyses). 20\% of studies were multinational studies that evaluated health care in more than one country (Germany), usually in the context of other European nations.

\section{Funding sources and disclosure of funding}

Figure 3 shows the distribution of funding statements and different types of sponsorship organizations by year range. Among those studies that included a clear funding statement $(n=120)$ the fraction of industry-sponsored 


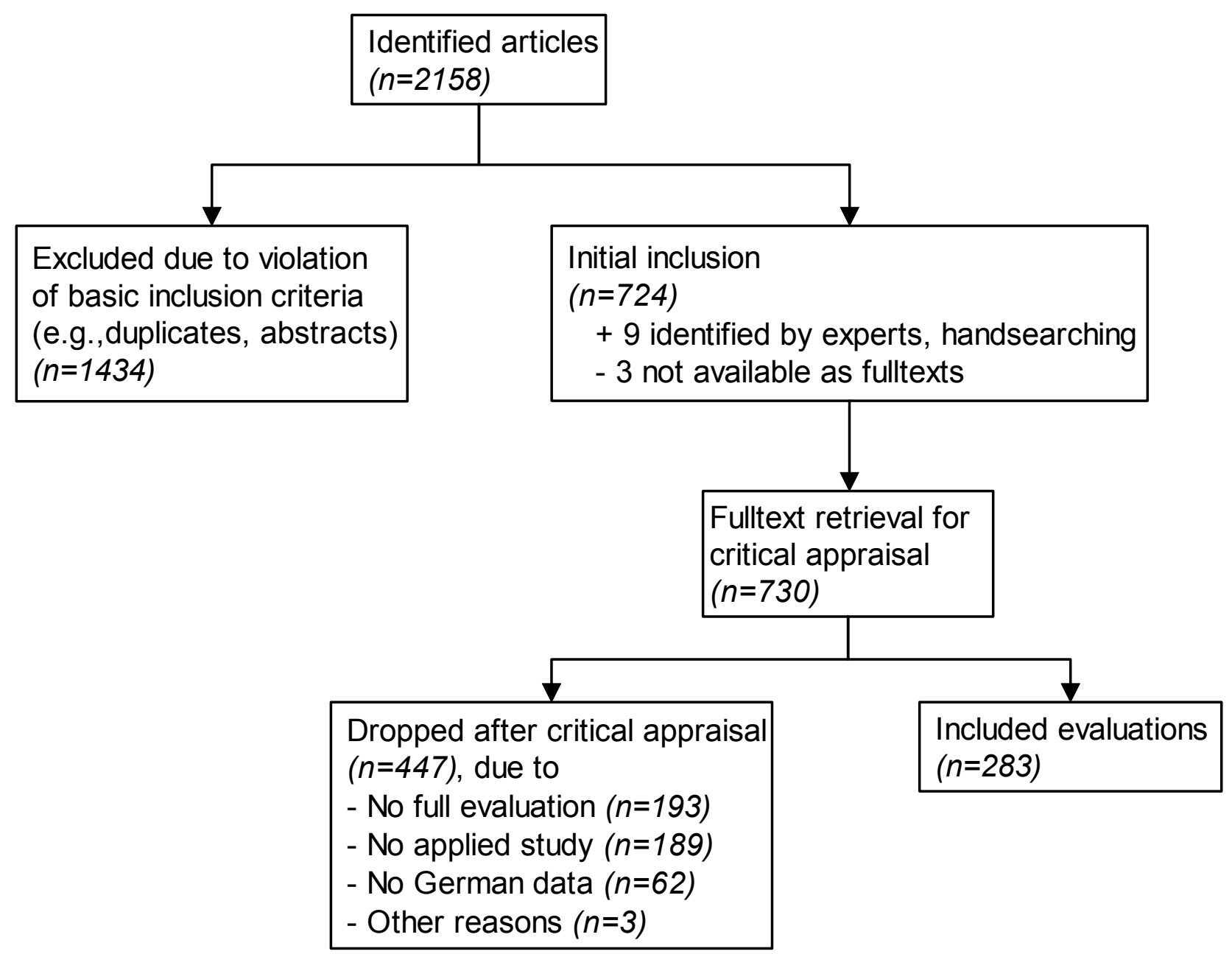

Figure I

Overview of in- and exclusion of studies.

studies is very high (77\%) and decreased only slightly (85\% in $1990-1998$ vs. $73 \%$ in studies published $1999-$ $2004, \mathrm{p}=0.572)$. For studies that evaluated pharmaceutical products, this figure is even higher (91\%). Declaration of sponsorship was strongly associated with journal specialty (35\% medical journal articles disclosing funding vs. $69 \%$ articles in health economic journals, $\mathrm{p}<0.001)$ and with article language (49\% of English articles vs. $29 \%$ of German-language articles, $\mathrm{p}<0.001)$. The fraction of German-language studies that declared funding increased from 23\% in articles published between 1990 and 1998 to $32 \%$ of studies published between 1999 and 2004 ( $\mathrm{p}=$ $0.340)$.

\section{Trends in published evaluations}

As can been seen from the comparison of studies published prior to 1999 and those published between 1999 and 2004, there seems to be a systematic trend towards more comprehensive methods of evaluation and study designs. Articles published after 1998 were more likely to be conducted alongside randomized controlled trials at the expense of modeling and observational studies (4\% vs. $16 \%, \mathrm{p}=0.009)$. We also observe differences in distribution of studies by primary ICD-9 category between the time periods. While the same five categories remain the most used ones, a distinct increase in studies evaluating care relating to nervous system and sense organ diseases 


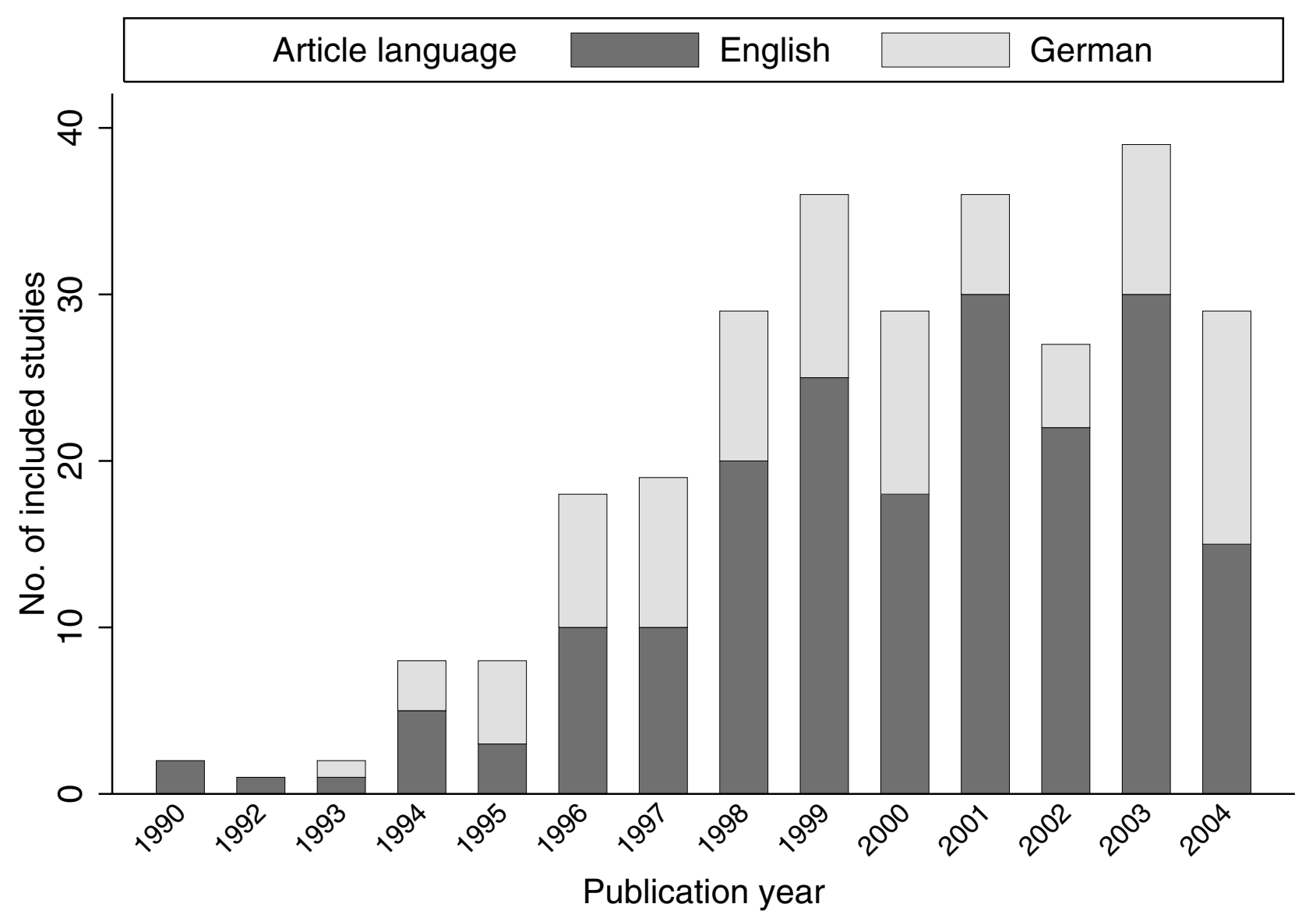

Figure 2

Included studies by article language and publication year.

results in a switch of ranks with the endocrine, nutritional and metabolic disease category. In addition, the later time period (1999-2004) is characterized by more diversity in studied ICD-9 categories as an increase in the "other" category documents. This variation may also be related to the strong increase in the assessment of medical procedures.

\section{Study perspective}

In less than half of all studies the authors explicitly reported the perspective the study was undertaken from, but this fraction significantly increased over time (41\% in $1990-1998$ vs. $62 \%$ in $1999-2004, \mathrm{p}<0.001)$. Study perspective reporting practice was strongly associated with journal specialty (35\% in medical journals vs. $69 \%$ in health care sciences journals, $\mathrm{p}<0.001$ ) and the observed shift is mainly attributable to changes in reporting practice in studies published in medical journals during the last years. However, not only the reporting of study perspective has significantly increased but also the distribu- tion of the different perspectives chosen by investigators. Considering only those studies that included a clear statement on the chosen perspective $(n=157)$, the fraction of studies undertaken from the more comprehensive societal perspective rose from $11 \%$ in the first to $20 \%$ in the second time period ( $\mathrm{p}=0.032)$. Of the 28 studies claimed to be undertaken from the societal perspective, 18 were costeffectiveness studies with clinical measures of effectiveness, 5 were cost-effectiveness studies with life years gained as outcome, 4 were cost-utility studies and the remaining was a cost-minimization study. This distribution indicates that the societal perspective manifested itself more frequently in a comprehensive costing methodology rather than in the societal valuation of benefits.

\section{Analysis of cost-utility studies}

Among the 18 identified cost-utility-studies, 16 were published in medical journals of which 3 articles were in German-language and 2 were published in health economic 
Table I: Distribution of included articles by journal and journal specialty

\begin{tabular}{|c|c|c|c|c|c|c|}
\hline & $1990-1998(n$ & 87) & 1999-2004 (n = & 196) & $1990-2004(n=$ & 283) \\
\hline & No. (\%) studies & & No. (\%) studies & & No. (\%) studies & \\
\hline \multicolumn{7}{|l|}{ By journal } \\
\hline Pharmacoeconomics (E H) & 10 & $(11.5)$ & 18 & $(9.2)$ & 28 & $(9.9)$ \\
\hline Medizinische Klinik (G M) & 9 & $(10.3)$ & 6 & $(3.1)$ & 15 & $(5.3)$ \\
\hline Gesundheitsökonomie \& Qual.mgmt (G H) & 1 & $(I .1)$ & 13 & $(6.6)$ & 14 & $(4.9)$ \\
\hline Deutsche Medizinische Wochenschrift (G M) & I & $(1.1)$ & 7 & $(3.6)$ & 8 & $(2.9)$ \\
\hline European Heart Journal (E M) & 2 & $(2.3)$ & 5 & $(2.6)$ & 7 & $(2.5)$ \\
\hline Other $(n=146$ journals)* & 64 & $(73.6)$ & 147 & $(75.0)$ & 211 & (74.6) \\
\hline \multicolumn{7}{|l|}{ By journal specialty } \\
\hline Medical journals & 70 & $(80.5)$ & 154 & $(78.6)$ & 224 & $(79.2)$ \\
\hline Health economics/services journals & 17 & $(19.5)$ & 42 & $(21.4)$ & 59 & (20.9) \\
\hline
\end{tabular}

* Summarized over extracted categories; (E) English-language journal; (G) German-language; (M) Medical journal; (H) Health economics/services journal

Table 2: Characteristics of included studies

\begin{tabular}{|c|c|c|c|c|c|c|}
\hline & $1990-1998(n$ & 87) & 1999-2004 (n & 196) & $1990-2004(n=$ & 283) \\
\hline & No. (\%) studies & & No. (\%) studies & & No. (\%) studies & \\
\hline \multicolumn{7}{|l|}{ By study type } \\
\hline Cost minimization & 16 & $(18.4)$ & 23 & $(11.7)$ & 39 & $(13.8)$ \\
\hline Cost consequence & 13 & $(14.9)$ & 34 & $(17.4)$ & 47 & (16.6) \\
\hline Cost effectiveness (life years gained) & 17 & $(19.5)$ & 35 & $(17.9)$ & 52 & $(18.4)$ \\
\hline Cost effectiveness (clinical outcome) & 38 & $(43.7)$ & 88 & $(44.9)$ & 126 & $(44.5)$ \\
\hline Cost utility & 3 & $(3.5)$ & 15 & $(7.7)$ & 18 & $(6.4)$ \\
\hline Cost benefit & 0 & $(0)$ & 1 & $(0.5)$ & 1 & $(0.4)$ \\
\hline \multicolumn{7}{|l|}{ By study design } \\
\hline Alongside RCT & 3 & $(3.5)$ & 31 & $(15.8)$ & 34 & $(12.0)$ \\
\hline Modeling study & 53 & $(60.9)$ & 101 & $(51.5)$ & 154 & $(54.4)$ \\
\hline Combination RCT/Modeling & 3 & $(3.5)$ & 15 & $(7.7)$ & 18 & $(6.4)$ \\
\hline Observational & 28 & $(32.2)$ & 49 & $(25.0)$ & 77 & $(27.2)$ \\
\hline \multicolumn{7}{|l|}{ By study perspective (as stated by authors) } \\
\hline Not stated & 51 & $(58.6)$ & 75 & $(38.3)$ & 126 & $(44.5)$ \\
\hline Third party payer (e.g., insurance) & 32 & $(36.8)$ & 83 & $(42.4)$ & 115 & $(40.6)$ \\
\hline Societal & 4 & $(4.6)$ & 24 & $(12.2)$ & 28 & $(9.9)$ \\
\hline Other (mainly 'patients')* & 0 & $(0)$ & 14 & $(7.1)$ & 14 & $(5.0)$ \\
\hline \multicolumn{7}{|c|}{ By disease category (ICD-9 category heading) } \\
\hline Circulatory system & 22 & $(25.3)$ & 35 & $(17.9)$ & 57 & $(20.1)$ \\
\hline Neoplasms & 13 & $(14.9)$ & 23 & $(11.7)$ & 36 & $(12.7)$ \\
\hline Infectious and parasitic & 12 & $(13.8)$ & 20 & $(10.2)$ & 32 & (II.3) \\
\hline Nervous system and sense organs & 4 & $(4.6)$ & 20 & $(10.2)$ & 24 & $(8.5)$ \\
\hline Endocrine, nutritional, metabolic & 7 & $(8.1)$ & 15 & $(7.7)$ & 22 & (7.8) \\
\hline Other* & 29 & $(33.3)$ & 83 & $(42.3)$ & 112 & $(39.6)$ \\
\hline \multicolumn{7}{|l|}{ By level of care } \\
\hline Curative & 63 & $(72.4)$ & 148 & $(75.5)$ & 211 & $(74.6)$ \\
\hline Rehabilitative & 2 & $(2.3)$ & 6 & $(3.1)$ & 8 & $(2.8)$ \\
\hline Preventive & 22 & $(25.3)$ & 42 & $(21.4)$ & 64 & $(22.6)$ \\
\hline \multicolumn{7}{|l|}{ By intervention type } \\
\hline Pharmaceutical & 49 & $(56.3)$ & 96 & $(49.0)$ & 145 & $(5 \mid .2)$ \\
\hline Medical procedure & 6 & $(6.9)$ & 38 & $(19.4)$ & 44 & $(15.6)$ \\
\hline Screening & 12 & (I3.8) & 16 & $(8.2)$ & 28 & $(9.9)$ \\
\hline Other* & 20 & $(23.0)$ & 46 & $(23.5)$ & 66 & $(23.3)$ \\
\hline
\end{tabular}

* Summarized over extracted categories 


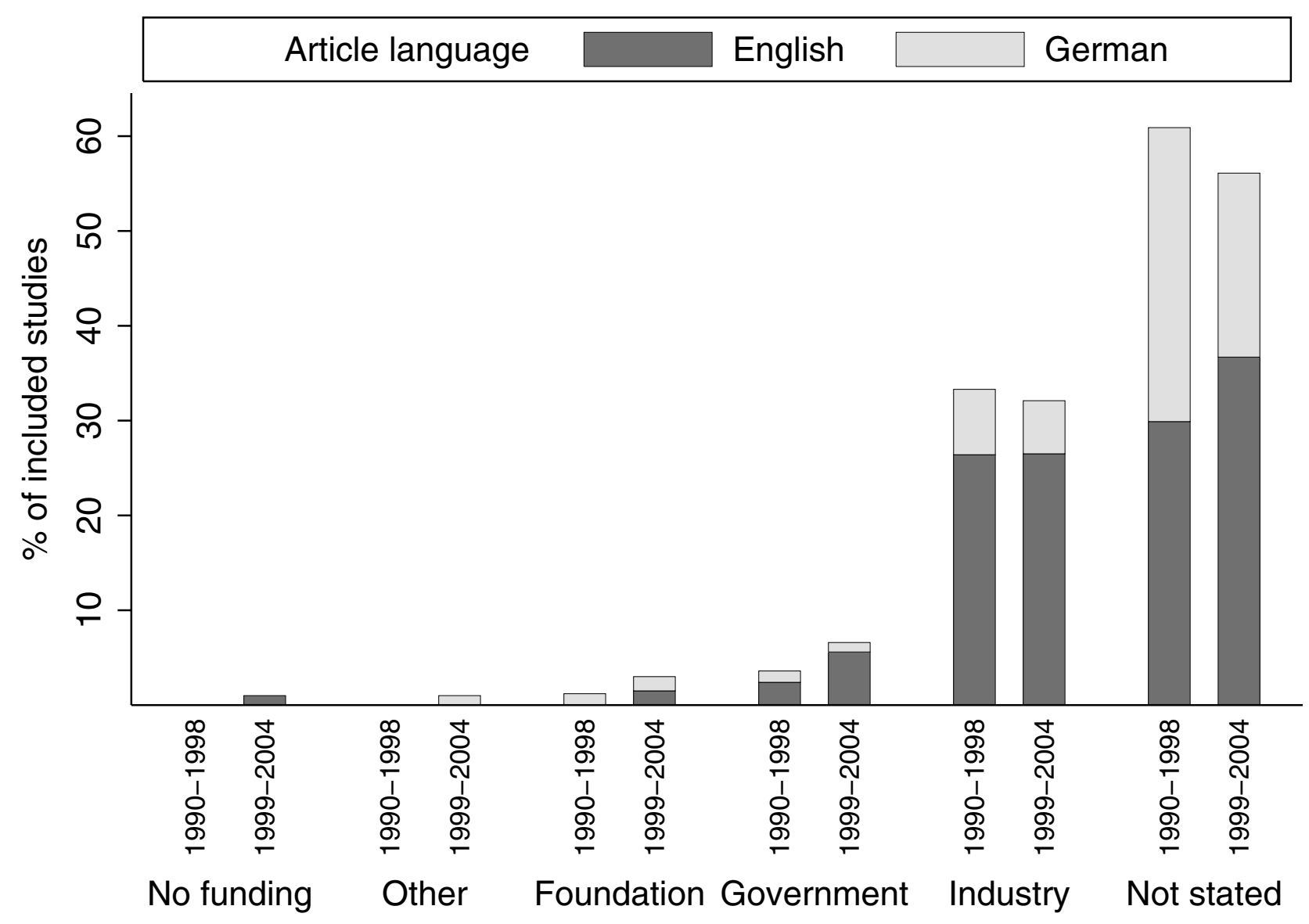

Figure 3

Included studies by funding statement, article language and publication year range.

journals. The methodology used to obtain utilities was very diverse and generally poorly reported. The vast majority of studies $(n=13)$ relied at least to some extent on secondary data but failed to provide even basic information on the methodology used in the secondary sources. In particular, most studies did not specify the original populations involved (e.g., sample size, country of origin, experts, patients or general public) and the relevant information was extracted by consulting the cited original sources. Four studies obtained primary data on patients' self-assessed quality-of-life or experts' assessment on behalf of their patients from small samples ( $n$ ranges between 22 patients and 70 experts). Quality-oflife data were then transformed into utilities using either disease category mapping to the Rosser-Matrix or empirically estimated transformations such as the Brazier function based on other nations' general population values [14]. Two modeling studies used a published transformation of disease-specific disability measures to time-trade off values originally obtained in a Canadian sample [15]. Two analyses referred to original studies that had used patients' quality-of-life assessment or experts' visual-analogue scale values from Sweden and Netherlands respectively and had applied a transformation or weighting ("social tariff") function based on health-related preferences from yet another country. Two studies used USAmerican values from multiple sources that were based on empirical analysis or expert judgment. Four studies relied completely on "judgment" without reference to secondary data or on published utility values for which it was unclear even from the original article whether these were empirically derived or based on judgment.

Four studies were classified as calculating quality-adjusted life years based on "primary data" of which three were modeling studies that referred to their quality-of-life data collection published elsewhere. Two of these articles published by the same working group report in their primary 
studies extensive quality-of-life assessment using different techniques in samples of 348 and 428 German patients. Utilities used for the base case of the analyses were derived by using patients' rating scale values and transforming these into utilities with the "Torrance" function which is based on preferences elicited via the standard-gamble in a sample of Canadian citizens [16]. Values obtained by other elicitation techniques and other samples (e.g., experts) had been used for sensitivity analyses. One study that referred to authors' primary data collection had elicited utilities in a sample of 21 German patients using the EuroQol instrument. However, only relative reductions in quality of life expressed as percentage points were documented. Finally, one analysis reported generation of primary data using the EQ-5D instrument (VAS and index) in samples of German patients. However, it is unclear how the authors estimated index values and which value set had been applied to calculate quality-adjusted life years. Measurements were obtained in two treatment arms and at multiple points in time and the respective sample sizes could not be determined.

In summary, in only three studies was the original methodology to obtain utilities well documented and comprehensible without consulting the original data sources. With the exception of one study, for which it could not be determined, no single study relied completely on German patients' or community health state preferences. Most concerning, a majority of studies mixed utilities elicited from various perspectives, nations and weighting approaches and did not actively disclose these sources of origin, e.g., by naming the populations in which preferences had originally been elicited.

\section{Discussion}

To the authors' knowledge, this is the first study that provides a systematic overview of German health economic evaluative studies. We found that about a third of included evaluations were published in German-language and can thus be expected to be missing in international reviews. In a review of Spanish economic evaluations of health care covering also earlier years of publication, the majority of studies (77\%) were published in local journals [17]. As Garcia-Altes we found that those national analyses that are published in local media are spread over a high number of journals and can predominantly be found in journals with a general bio-medical background. However, our key findings are in concordance with the results of international analyses of the literature. As others, we found that the majority of economic appraisals concentrate on few disease categories [18]. While these categories do reflect the current burden of disease in western societies, some important health areas have gained only limited attention [19]. For example, musculoskeletal, mental and pulmonary diseases are strongly underrep- resented in the German economic evaluation literature though they bear a heavy burden that is even likely to increase in the future. Similarly, the fraction of studies that examined rehabilitative care is small and has remained stable over the past 14 years. These results may not only be explained by authors' research interests or awareness regarding certain areas of health and health care, but may also be related to the interests of funding bodies.

The fact that three quarters of all studies and nearly all studies evaluating pharmaceuticals that included a funding statement were industry-sponsored is concerning. The biases associated with industry-sponsorship have been acknowledged as being problematic internationally [2024]. Bell et al. recently systematically assessed publication bias in health economic evaluations and found that most published analyses report favourable incremental cost effectiveness ratios below 20,000 \$/QALY [25]. Studies funded by industry were more likely to report ratios below the three analyzed thresholds ( $(20,000 \$ /$ QALY adjusted odds ratio 2.1, 95\% confidence interval 1.3-3.3), 50,000 \$/QALY (3.2, 1.8-5.7), and 100,000 \$/QALY (3.3, 1.6$6.8)$ ). Compared to the international literature, the potential influence of industry-sponsoring in Germany seems more advanced. In an analysis of evaluations included in the HEED database that were published between 19922001, Pritchard reports that government and publicly funded policy making bodies are the most important source of funds being involved in $40 \%$ of studies, followed by the pharmaceutical industry at around one third [26]. As in our study, industry funding is more frequent in the evaluation of pharmaceuticals but at a considerable lower level (57\% in studies published 1997-2001). This important role of the pharmaceutical industry in funding may in part explain why certain health problems or aspects of care delivery, e.g., rehabilitative care, are underrepresented in health economic studies. The finding that funding and publication bias is not only inherent in what is being evaluated but also associated with the results in terms of favorability of health care interventions calls the realistic value of health economic evaluations for decision makers seriously into question.

Our study indicates a systematic trend towards more comprehensive methods of evaluation, study perspectives and study designs. Though this result is encouraging, it has to be interpreted cautiously. "Comprehensiveness" is not in itself an exclusive goal and must be accompanied by methodological rigor in study design, model building, data collection and other aspects. However, as a limitation of our study, we extracted data on study characteristics and did not explicitly assess the quality of studies, e.g., by approving methods to calculate costs. For example, the observed increase in clear statements regarding study per- 
spective can clearly be regarded a development towards quality of reporting. However, we did not qualitatively verify whether authors' statements regarding study perspective were justified. And even in case the labeling of perspective was justified, this does not necessarily imply that the chosen perspective itself was appropriate to the study question.

Regarding key aspects of methodology reporting in health economic studies, our study also confirms the findings of Neumann et al. who analyzed adherence to recommended reporting practice in English-language cost-utility studies published between 1976-1997 and 1998-2001 [1]. As Neumann et al., we observed an increase in authors' presentation of study perspective over the years. The fraction of studies that clearly report study perspective in German analyses published 1999-2004 (62\%) is still considerably lower than in English-language international cost-utility analyses published 1998-2001 (73\%), but much higher than the figure that has been reported for Spanish economic evaluations published 1969-1999 (27\%) [17]. Also in concordance with Neumann et al., the frequency of statements of funding source disclosure in analyses pertaining to Germany remained stable over the years.

As reported for the international literature, there is extensive variation in the methodology used for health measurement and preference elicitation in German cost-utility studies [1,27-29]. Cost-utility-analysis is a methodological challenge and the techniques for utility elicitation and calculation of QALYs can be demanding and complex. Appropriate study design and reporting of methodology is therefore crucial, but has been questioned in reviews of the international literature [30]. Two key aspects can be concluded from our analysis: First, due to the diversity in methodology, quality-adjusted life years calculated in different studies are not comparable and compatible with each other. Second, the vast majority of studies cannot be termed as assessing health benefits from German patients' or the German population perspective. This is problematic since intercultural differences in health state preferences have been observed [31-34]. For example, Greiner et al. recently investigated differences in time-trade off (TTO) values for EuroQol health states between the German general population and the British "social tariff" published by Dolan et al. [35,36]. The authors report that German and British TTO values were significantly different for 30 out of 35 health states with the German values being systematically higher than the UK values. Most concerning, instead of basing the calculation of QALYs consistently on utilities that were obtained in a single European neighbor population as response to a lack of primary German data, many analyses included in our review mixed multiple sources. It can only be hoped for that recent efforts to estimate European and German "tariffs" will increase consistency in QALY calculations in the future $[37,38]$. Recent analyses of the international costutility literature suggest a trend towards the increased use of generic health status instruments and the elicitation of preferences in community samples [39]. Besides these considerations relating to study design itself, the adherence to recommended reporting practices remains a serious problem. As Richardson and Manca, who undertook a review of cost-utility-studies conducted alongside randomized clinical trials, we observed an alarming flaw in the reporting of key methodological aspects in cost-utilitystudies [10]. Gerald et al. report in a review of international cost-utility analyses published in 1996 that in nearly $90 \%$ of studies, authors had clearly described how quality-of-life weights were assigned [30]. In contrast to this quite satisfactory figure, we often had to consult two and more secondary studies to gain insight into the very basic question of preference elicitation, namely: Who has been asked what? to derive utility weights. Due to a lack of transparency, e.g., through "chain referencing", many of the outlined deficits cannot easily be discovered by readers, in particular those unfamiliar with health economics. Given that the majority of studies are published in medical journals, and a further diffusion into medical subspecialty journals can be expected, responsibility of editors and peer-reviewers in the process of publishing is therefore essential $[30,40,41]$. Specialized health economic databases, such as the NHS-EED, OHE-HEED or the recently established European Network of Health Economic Evaluation Databases (EURONHEED) that include additional, standardized review of study methodology and data sources may become increasingly important tools to assess study quality after publication $[42,43]$.

\section{Conclusion}

Many of the German-language evaluations included in our study are likely to be missing in international reviews and may be systematically different from English-language reviews from Germany. Lack of transparency and adherence to recommended reporting practices constitute a serious problem in German economic evaluations.

\section{Competing interests}

The author(s) declare that they have no competing interests.

\section{Authors' contributions}

DLBS and TAB conceived of the study and participated in its design. Both authors conducted the literature review. TAB coordinated data retrieval and extraction. DLBS performed the statistical analysis and drafted the manuscript. Both authors read and approved the final manuscript. 


\section{Additional material}

\section{Additional File 1}

Search strategies used. The table provides the details of search strings, combinations and delimiters of the literature search for each database approached.

Click here for file

[http://www.biomedcentral.com/content/supplementary/1472-

6963-7-7-S1.pdf]

\section{Acknowledgements}

We thank all colleagues that responded to our request and provided us their bibliographic data for their support. The valuable comments of two referees are acknowledged. DLBS received financial support for this study by a grant from the German Ministry for Research and Technology (BMBF, \#JP2004 W). The views expressed are the sole responsibility of the author. The funding source had no influence on study design; in the collection, analysis, and interpretation of the data; in the writing of the manuscript; and in the decision to submit the manuscript for publication.

\section{References}

I. Neumann PJ, Greenberg D, Olchanski NV, Stone PW, Rosen AB: Growth and Quality of the Cost-Utility Literature, 1976200I. Value Health 2005, 8:3-9.

2. Barbieri M, Drummond M, Willke R, Chancellor J, Jolain B, Towse A: Variability of Cost-Effectiveness Estimates for Pharmaceuticals in Western Europe: Lessons for Inferring Generalizability. Value Health 2005, 8:10-23.

3. Rosen AB, Greenberg D, Stone PW, Olchanski NV, Neumann PJ: Quality of abstracts of papers reporting original cost-effectiveness analyses. Med Decis Making 2005, 25:424-428.

4. Stone PW, Chapman RH, Sandberg EA, Liljas B, Neumann PJ: Measuring costs in cost-utility analyses. Variations in the literature. Int J Technol Assess Health Care 2000, I 6: I I I-I 24.

5. Hill SR, Mitchell AS, Henry DA: Problems with the interpretation of pharmacoeconomic analyses. JAMA 2000, 283:2| |6-2|2|.

6. Doshi JA, Glick HA, Polsky D: Analyses of cost data in economic evaluations conducted alongside randomized controlled trials. Value Health 2006, 9:334-340.

7. Armstrong R, Jackson N, Doyle J, Waters E, Howes F: Its in your hands: the value of handsearching in conducting systematic reviews of public health interventions. J Public Health (Oxf) 2005, 27:388-39l.

8. Pignone M, Saha S, Hoerger T, Lohr KN, Teutsch S, Mandelblatt J: Challenges in systematic reviews of economic analyses. Ann Intern Med 2005, 142:1073-1079.

9. Sassi F, Archard L, McDaid D: Searching literature databases for health care economic evaluations: how systematic can we afford to be? Med Care 2002, 40:387-394.

10. Richardson G, Manca A: Calculation of quality adjusted life years in the published literature: a review of methodology and transparency. Health Econ 2004, I 3:1203-1210.

II. Stalmeier PF, Goldstein MK, Holmes AM, Lenert L, Miyamoto J, Stiggelbout AM, Torrance GW, Tsevat J: What should be reported in a methods section on utility assessment? Med Decis Making 2001, 2 I:200-207.

12. Stata Corp: Stata Statistical Software: Release 9.0 College Station, TX: Stata Corporation; 2005.

13. Landis JR, Koch GG: The measurement of observer agreement for categorical data. Biometrics 1977, 33:159-174.

14. Brazier J, Roberts J, Deverill M: The estimation of a preferencebased measure of health from the SF-36. J Health Econ 2002, 21:27I-292.

15. Sharma S, Brown GC, Brown MM, Shah GK, Snow K, Brown H, Hollands $\mathrm{H}$ : Converting visual acuity to utilities. Can J Ophthalmol 2000, 35:267-272.
16. Torrance GW, Feeny DH, Furlong WJ, Barr RD, Zhang Y, Wang Q: Multiattribute utility function for a comprehensive health status classification system. Health Utilities Index Mark 2. Med Care 1996, 34:702-722.

17. Garcia-Altes A: Twenty years of health care economic analysis in Spain: are we doing well? Health Econ 200I, I 0:715-729.

18. Siegel JE, Byron SC, Lawrence WF: Federal Sponsorship of CostEffectiveness and Related Research in Health Care: 1997200 I. Value Health 2005, 8:223-236.

19. Neumann PJ, Rosen AB, Greenberg D, Olchanski NV, Pande R, Chapman RH, Stone PW, Ondategui-Parra S, Nadai J, Siegel JE, et al:: Can we better prioritize resources for cost-utility research? Med Decis Making 2005, 25:429-436.

20. Lexchin J, Bero LA, Djulbegovic B, Clark O: Pharmaceutical industry sponsorship and research outcome and quality: systematic review. BMJ 2003, 326: I I67-II70.

21. Friedberg M, Saffran B, Stinson TJ, Nelson W, Bennett CL: Evaluation of conflict of interest in economic analyses of new drugs used in oncology. JAMA |999, 282: |453-|457.

22. Baker CB, Johnsrud MT, Crismon ML, Rosenheck RA, Woods SW Quantitative analysis of sponsorship bias in economic studies of antidepressants. Br J Psychiatry 2003, I 83:498-506.

23. Schwappach DL, Koeck CM: Selective COX-2 inhibitors: a health economic perspective. Wien Med Wochenschr 2003, 153:116-122.

24. Knox KS, Adams JR, Djulbegovic B, Stinson TJ, Tomor C, Bennet CL: Reporting and dissemination of industry versus non-profit sponsored economic analyses of six novel drugs used in oncology. Ann Oncol 2000, I I:I59|-I595.

25. Bell CM, Urbach DR, Ray JG, Bayoumi A, Rosen AB, Greenberg D, Neumann PJ: Bias in published cost effectiveness studies: systematic review. BMJ 2006, 332:699-703.

26. Pritchard C: Developments in economic evaluation in health care: $A$ review of HEED London: Office of Health Economics (OHE); 2004.

27. Griebsch I, Coast J, Brown J: Quality-adjusted life-years lack quality in pediatric care: a critical review of published costutility studies in child health. Pediatrics 2005, I I 5:e600-e6 |4

28. Neumann PJ, Stone PW, Chapman RH, Sandberg EA, Bell CM: The quality of published cost-utility analyses, 1976-1997. Ann Intern Med 2000, I32:964-972.

29. Neumann PJ, Zinner DE, Wright JC: Are Methods for estimating QALYs in cost-effectiveness analyses improving? Med Decis Making 1997, I 7:402-408.

30. Gerard K, Smoker I, Seymour J: Raising the quality of cost-utility analyses: lessons learnt and still to learn. Health Policy 1999, 46:217-238

31. Greiner W, Claes C, Busschbach JJ, Graf von der Schulenburg JM: Validating the EQ-5D with time trade off for the German population. Eur J Health Econ 2004.

32. Badia X, Roset M, Herdman M, Kind P: A comparison of United Kingdom and Spanish general population time trade-off values for EQ-5D health states. Med Decis Making 200 I, 2 I:7-16.

33. Johnson JA, Ohinmaa A, Murti B, Sintonen H, Coons SJ: Comparison of Finnish and U.S.-based visual analog scale valuations of the EQ-5D measure. Med Decis Making 2000, 20:28I-289.

34. Tsuchiya A, Ikeda S, Ikegami N, Nishimura S, Sakai I, Fukuda T, Hamashima C, Hisashige A, Tamura M: Estimating an EQ-5D population value set: the case of Japan. Health Econ 2002, I I:34 |-353.

35. Greiner W, Claes C, Busschbach JJ, Graf von der Schulenburg JM: Validating the EQ-5D with time trade off for the German population. Eur J Health Econ 2004.

36. Dolan P: Modeling valuations for EuroQol health states. Med Care 1997, 35:1095-1108.

37. Greiner W, Weijnen T, Nieuwenhuizen M, Oppe S, Badia X, Busschbach J, Buxton M, Dolan P, Kind P, Krabbe P, et al.: A single European currency for EQ-5D health states. Results from a sixcountry study. Eur J Health Econ 2003, 4:222-23I.

38. Greiner W, Claes C, Busschbach JJ, Graf von der Schulenburg JM: Validating the EQ-5D with time trade off for the German population. Eur J Health Econ 2005, 6: I 24- I30.

39. Brauer CA, Rosen AB, Greenberg D, Neumann PJ: Trends in the Measurement of Health Utilities in Published Cost-Utility Analyses. Value Health 2006, 9:213-218. 
40. Sonnad SS, Greenberg D, Rosen AB, Neumann PJ: Diffusion of published cost-utility analyses in the field of health policy and practice. Int J Technol Assess Health Care 2005, 21:399-402.

41. Greenberg D, Pliskin JS: Preference-based outcome measures in cost-utility analyses. A 20-year overview. Int J Technol Assess Health Care 2002, 18:46I-466.

42. de Pouvourville G, Ulmann P, Nixon J, Boulenger S, Glanville J, Drummond M: The Diffusion of Health Economics Knowledge in Europe : The EURONHEED (European Network of Health Economics Evaluation Database) Project. Pharmacoeconomics 2005, 23: II 3-1 20.

43. Nixon J, Ulmann P, Glanville J, Boulenger S, Drummond M, de PG: The European Network of Health Economic Evaluation Databases (EURO NHEED) Project. Eur J Health Econ 2004, 5:183-187.

\section{Pre-publication history}

The pre-publication history for this paper can be accessed here:

http://www.biomedcentral.com/1472-6963/7/7/prepub

Publish with Bio Med Central and every scientist can read your work free of charge

"BioMed Central will be the most significant development for disseminating the results of biomedical research in our lifetime. "

Sir Paul Nurse, Cancer Research UK

Your research papers will be:

- available free of charge to the entire biomedical community

- peer reviewed and published immediately upon acceptance

- cited in PubMed and archived on PubMed Central

- yours - you keep the copyright

Submit your manuscript here:

http://www.biomedcentral.com/info/publishing_adv.asp 